\title{
Neutrophil proteinases and rhDNase therapy in cystic fibrosis
}

\author{
C. Vogelmeier*, G. Döring**
}

The severity of lung involvement is crucial for the prognosis of patients suffering from the common hereditary disorder cystic fibrosis $(\mathrm{CF})$. It is currently believed that the more or less rapid loss of lung function in $\mathrm{CF}$ patients is caused by a critical reduction of mucociliary clearance, due to viscous secretions and persistent bacterial endobronchial infections Pseudomonas aeruginosa and Staphylococcus aureus, are the predominant pathogens [1]. The vigorous host response to these pathogens is characterized by a high influx of blood neutrophils into the airway lumen. Unable to resolve the infection in the airway, the intruding neutrophils soon decay nonapoptotically. The release of cross-linking deoxyribonucleic acid (DNA) and filamentous actin from these cells further increases the viscosity of the sputum. Rather than bacterial toxins, which are soon neutralized by specific antibodies, neutrophil products have been implicated in various pathogenetically important reactions that lead to airway destruction.

A central role in the pathophysiology of $\mathrm{CF}$ and other inflammatory disorders has been attributed to neutrophil elastase. This serine protease is stored in intracellular granules of mature neutrophils. Its physiological function is to degrade phagocytosed proteins. However, during neutrophil stimulation, e.g. during the process of phagocytosis, neutrophil elastase and other enzymes may escape from the phagolysosome and reach the extracellular space, where they may cause substantial damage to the surrounding lung tissue, inhibit cell functions, and inactivate molecules relevant to the integrity of the lung [1].

In order to prevent the detrimental effects of neutrophil proteinases, the human lung is protected by several antiproteinases, such as $\alpha_{1}$-proteinase inhibitor $\left(\alpha_{1}\right.$-PI) and secretory leucoprotease inhibitor (SLPI). In the noninflamed human lung, the antiproteinase activity generated by these molecules by far outweighs the proteinase activity. But this surplus may get lost: besides releasing proteinases, stimulated neutrophils secrete reactive oxygen metabolites and the oxidation enzyme, myeloperoxidase. As both $\alpha_{1}$-PI and SLPI carry a methionine residue in their active centre, they are vulnerable to oxidative inactivation $[2,3]$. Additionally, in clinical conditions with an enormous proteinase burden, proteinases may use proteinase inhibitors as substrates and

*Pneumologische Abteilung, Medizinische Klinik I, Klinikum Grosshadern, Ludwig-Maximilians-Universität München, Germany and **Abteilung Allgemeine Hygiene und Umwelthygiene, Hygiene Institut, Eberhard-Karls-Universität, Tübingen, Germany.

Correspondence: C. Vogelmeier, Pneumologische Abteilung, Medizinische Klinik I, Klinikum Grosshadern, University of Munich, Marchioninistrasse 15, 81366 Munich, Germany inactivate them by proteolytic cleavage. Thus, given certain pathophysiological conditions, the antiproteinase shield of the lung may be overwhelmed.

$\mathrm{CF}$ is the classic example for such a condition. In the chronically infected and inflamed CF lung, persistent neutrophil stimulation by host and bacterial components leads to concentrations of more than $100 \mu \mathrm{g}$ of active neutrophil elastase per millilitre of sputum [4], whereas $\alpha_{1}$-PI $[4,5]$ and SLPI $[3,6]$ are enzymatically inactive and degraded. These events may start very early in the life of a CF patient, since elevated levels of neutrophil elastase have been found in patients younger than 6 months [7, 8]. Later in life, an increased load of neutrophil elastase may be present not only in severely diseased patients but also in stable individuals with clinically mild lung disease [9]. Neutrophil elastase has been shown to degrade nearly all structural proteins of the lung, including elastin, collagen type I-IV, fibronectin and proteoglycans, exerts direct toxic effects on endothelial cells, and decreases ciliary motility, thereby facilitating bacterial colonization [8,10-12]. The detection of elastin split products (desmosines) in urine samples of CF patients suggests that cleavage of elastin actually occurs in vivo [13]. Most importantly, the presence of elastin split products correlated with the severity of lung disease. Neutrophil elastase may also inactivate several components of the immune system, such as immunoglobulins, immune complexes, complement components [8] and cell surface receptors on neutrophils [14], leaving them nearly incapable of opsonizing and eliminating bacterial pathogens. These phenomena may explain, at least in part, why the lungs of CF patients are chronically colonized with bacteria. In addition, neutrophil elastase may recruit increasing numbers of neutrophils to the lung by stimulating bronchial epithelial cells to synthesize and secrete interleukin-8 (IL-8), a potent chemoattractant for neutrophils [15].

Together with glycoconjugates or mucins from hypersecreting mucosal glands, DNA [16] and filamentous actin [17] released from decaying neutrophils considerably increase the sputum viscosity. The heroic approach to repeatedly clearing the obstructed bronchi by bronchoalveolar lavage has now been substituted in many $\mathrm{CF}$ patients by aerosolization of recombinant human deoxyribonuclease (rhDNase). In clinical trials with rhDNase, a marked reduction in sputum viscosity accompanied by a small but significant improvement in lung function was achieved [18]. However, the initial hope that treating CF patients with rhDNase would lead to a dramatic decrease in number and/or concentration of bacteria, neutrophils, neutrophil products, including elastase and proinflammatory cytokines, remained largely elusive. 
When the clinical trials evaluating efficacy of aerosolized rhDNase in CF were underway, based on in vitro studies, the hypothesis evolved that this form of therapy may actually increase serine proteinase activity in the airways [19]. How could rhDNase interfere with neutrophil proteinases? Both neutrophil elastase and even more so cathepsin G, another lysosomal serine proteinase from neutrophils, are cationic molecules which may be bound and inhibited by negatively charged polyanions, such as DNA. Thus, cleavage of DNA may result in a significant release of serine proteinases, which in turn may cause enhanced proteolytic activity.

In this issue of the Journal, Rochat et al. [20] readdress the question of how treating CF patients with rhDNase affects the neutrophil proteinase burden of the lung. Sputum samples obtained from CF patients before, during and after therapy were analysed for neutrophil elastase and cathepsin G activity. Both parameters showed a remarkable rise following the start of the therapy and a moderate decline after the end of the treatment supporting the findings of KUEPPERS and FIEL [19]. The changes were not attributable to infectious exacerbations, since bacterial counts in sputum slightly decreased during rhDNase therapy. These findings are clearly contradictory to those reported in two recently published papers [21, 22]. SнAн and co-workers [21] found a significant increase of elastolytic activity 1 day after onset of rhDNase therapy, whereas after 6 months of treatment elastolytic activity was significantly lower than at baseline. In accordance with these data, Costello et al. [22] described an overall $40 \%$ decline of the neutrophil elastase burden in CF sputum samples during rhDNase therapy.

What could be the reason for these conflicting data? From a technical standpoint, all three groups used similar assays to measure neutrophil elastase activity in the sputum samples. The methods for sputum sampling and propagation were different, potentially causing differences in the observed neutrophil elastase activities and concentrations. Thus, for example, immediate propagation of expectorated sputum may reduce release of elastase from decaying neutrophils in vitro and adding dithiothreitol to solubilized sputum may increase elastase yields. Similarly, centrifugation at different accelerations may affect the results. However, these methodological issues cannot cause increases or decreases of enzyme levels observed within a study, where the sampling and processing techniques, once chosen, remain constant.

Does the severity of the disease influence the results? ShaH and co-workers [21] and Costello et al. [22] included patients with mild-to-moderate pulmonary disease as indicated by a forced vital capacity (FVC) of $>40 \%$ predicted. Rochat et al. [20] included patients with a forced expiratory volume in one second (FEV1) of $20-44 \%$ predicted, representing moderate-to-severe lung disease. Several studies have shown a direct relationship between severity of lung disease and sputum levels of neutrophil elastase $[6,23]$. Indeed, CF patients evaluated by ROCHAT et al. [20] had elastase activity levels in sputum samples obtained before initiation of rhDNase therapy that were about one order of magnitude higher than in the study by Costello et al. [22]. Unfortunately, Rоснат et al. [20] do not mention lung function data under therapy. Other authors reported that after 14 days of rhDNase therapy individuals with mildto-moderate lung disease showed a significant improvement in lung function, whereas lung function parameters did not significantly change in patients with severe lung disease [24]. Is this observation a consequence of an increased load of neutrophil proteinases?

Based on the fact that rhDNase reduces sputum viscosity, thereby increasing clearance, one would expect a significant reduction of the sputum volume after longterm rhDNase therapy. In contrast, Rochat et al. [22] report that the amount of sputum was not significantly different before, during and after rhDNase therapy. The rise in serine proteinase levels observed by the authors may explain this phenomenon. Since neutrophil elastase and cathepsin $\mathrm{G}$ are both potent secretagogues [25], increasing levels of active neutrophil proteinases may further augment hypersecretion in the airways of $\mathrm{CF}$ patients leading to a rise in sputum volume. This effect may counterbalance the reduction in sputum viscosity that is induced by rhDNase.

Notwithstanding all of these considerations, the sputum levels of neutrophil elastase under rhDNase therapy observed by Rochat et al. [20], SHAH and co-workers [21] and Costello et al. [22] are in a very high range. Thus, we agree with Rоснат et al. [20] that, besides treating CF airways disease with antibiotics, bronchodilators, rhDNase, mucolytics and physiotherapeutic techniques, effective and safe strategies directed against the inflammatory process are warranted. As the neutrophil is the main culprit in this context, the goal is an anti-inflammatory therapy that reduces neutrophils and/or neutrophil products. A multicentre trial of corticosteroid therapy was soon stopped due to unacceptable side-effects [26]. A well-controlled trial of the nonsteroidal anti-inflammatory agent, ibuprofen, demonstrated that the drug was effective in slowing the progression of lung disease [27]. Another logical approach is the use of proteinase inhibitors. So far, two small scale, short-term studies with antiproteinases have been published. When a recombinant human SLPI (rhSLPI) was aerosolized to CF patients, the concentrations of IL-8 and the neutrophil numbers in bronchoalveolar lavage fluid samples declined remarkably [28]. In another study by the same group, $\alpha_{1}$-PI purified from human plasma was aerosolized to CF patients [29]. When 12 patients received $1.5-3.0 \mathrm{mg} \cdot \mathrm{kg}^{-1}$ every $12 \mathrm{~h}$ for 1 week, neutrophil elastase activity was suppressed and purified neutrophils, incubated with bronchoalveolar lavage fluid obtained under therapy, showed a normal capacity to phagocytose Pseudomonas aerugin-osa. Based on these and other data [30], long-term controlled clinical trials evaluating the efficacy and safety of antiproteinases, such as, $\alpha_{1}$-proteinase inhibitor or recombinant secretory leucoprotease inhibitor, are mandatory.

\section{References}

1. Döring G, Knight R, Bellon G. Immunology of cystic fibrosis. In: Cystic Fibrosis. Hodson ME, Geddes GM, eds. London, Chapman and Hall, 1994; pp. 99-129.

2. Matheson NR, Wong PS, Travis J. Enzymatic inactivation of human alpha ${ }_{1}$-proteinase inhibitor by neutrophil myeloperoxidase. Biochem Biophys Res Commun 1979; 88: 402-409. 
3. Vogelmeier C, Hubbard RC, Fells GA, et al. Antineutrophil elastase defense of the normal human respiratory epithelial surface provided by the secretory leukoprotease inhibitor. J Clin Invest 1991; 87: 482-488.

4. Goldstein W, Döring G. Lysosomal enzymes from polymorphonuclear leukocytes and proteinase inhibitors in patients with cystic fibrosis. Am Rev Respir Dis 1986; 134: 49-56.

5. Suter S, Chevallier I. Proteolytic inactivation of alpha ${ }_{1}^{-}$ proteinase inhibitor in infected bronchial secretions from patients with cystic fibrosis. Eur Respir J 1991; 4: 40-49.

6. Suter S, Schaad UB, Tegner H, Ohlsson K, Desgrandchamps D, Waldvogel FA. Levels of free granulocyte elastase in bronchial secretions from patients with cystic fibrosis: effect of antimicrobial treatment against Pseudomonas aeruginosa. J Infect Dis 1986; 153: 902909.

7. Kahn TZ, Wagener JS, Bost T, Martinez J, Accurso FJ, Riches DHW. Early pulmonary inflammation in infants with cystic fibrosis. Am J Respir Crit Care Med 1995; 151: 1075-1082.

8. Birrer P, McElvaney NG, Rüdeberg C, et al. Proteaseantiprotease imbalance in the lungs of children with cystic fibrosis. Am J Respir Crit Care Med 1994; 150: 207-213.

9. Konstan MW, Hilliard KA, Norvell TM, Berger M. Bronchoalveolar lavage findings in cystic fibrosis patients with stable, clinically mild lung disease suggest ongoing infection and inflammation. Am J Respir Crit Care Med 1994; 150: 448-454.

10. Weiss SJ. Tissue destruction by neutrophils. $N$ Engl $J$ Med 1989; 320: 365-376.

11. Janoff A, White R, Carp H, Harel S, Dearing R, Lee D. Lung injury induced by leukocytic proteases. Am J Pathol 1979; 97: 111-129.

12. Travis J. Structure, function, and control of neutrophil proteinases. Am J Med 1988; 84: 37S-41S.

13. Bruce MC, Poncz L, Klinger JD, Stern RC, Tomashefski JR Jr, Dearborn DG. Biochemical and pathological evidence for proteolytic destruction of lung connective tissue in cystic fibrosis. Am Rev Respir Dis 1985; 132: 529-535.

14. Berger M, Sorensen RU, Tosi MF, Dearborn DG, Döring G. Complement receptor expression on neutrophils at an inflammatory site, the pseudomonas-infected lung in cystic fibrosis. J Clin Invest 1989; 84: 1302-1313.

15. Nakamura H, Yoshimura K, McElvaney NG, Crystal RG. Neutrophil elastase in respiratory epithelial lining fluid of individuals with cystic fibrosis induces interleukin-8 gene expression in a human bronchial epithelial cell line. J Clin Invest 1992; 89: 1478-1484

16. Shak S, Capon DJ, Hellmiss R, Marsters SA, Baker CL. Recombinant human DNase I reduces the viscosity of cystic fibrosis sputum. Proc Natl Acad Sci USA 1990; 87: 9188-9192.

17. Vasconcellos CA, Allen PG, Wohl ME, Drazen JM, Janmey PA, Stossel TP. Reduction in viscosity of cystic fibrosis sputum in vitro by gelsolin. Science 1994; 263: 969-971.

18. Fuchs HJ, Borowitz DS, Christiansen DH, Morris EM, Nash ML, Ramsey BW. Effect of aerosolised recombinant human DNase on exacerbations of respiratory symptoms and on pulmonary function in patients with cystic fibrosis. N Engl J Med 1994; 331: 637-642.

19. Kueppers F, Fiel SB. Proteolytic activity of purulent secretions in patients with $\mathrm{CF}$ and bronchitis is increased by DNase. Am Rev Respir Dis 1992; 145: A563.

20. Rochat Th, Dayer Pastore F, Schlegel-Haueter SE, et al. Aerosolized rhDNase in cystic fibrosis: effect on leucocyte proteases in sputum. Eur Respir J 1996; 9: 2200-2206

21. Shah PL, Scott SF, Knight RA, Hodson ME. The effects of recombinant human DNase on neutrophil elastase activity and interleukin- 8 levels in the sputum of patients with cystic fibrosis. Eur Respir J 1996; 9: 531-534.

22. Costello CM, O'Connor CM, Finlay GA, Shiels P, FitzGerald MX, Hayes JP. Effect of nebulised recombinant DNase on neutrophil elastase load in cystic fibrosis. Thorax 1996; 51: 619-623.

23. O'Connor CM, Gaffney K, Keane J, et al. $\alpha_{1}$-proteinase inhibitor, elastase activity, and lung disease severity in cystic fibrosis. Am Rev Respir Dis 1993; 148: 1665-1670

24. Shah PL, Scott SF, Hodson ME. Report on a multicenter study using aerosolised recombinant human DNase I in the treatment of cystic fibrosis patients with severe pulmonary disease. Pediatr Pulmonol 1993; (Suppl. 9): 153-158.

25. Sommerhoff CP, Nadel JA, Basbaum CB, Caughey GH. Neutrophil elastase and cathepsin G stimulate secretion from cultured bovine airway gland serous cells. J Clin Invest 1990; 85: 682-689.

26. Rosenstein BJ, Eigen H. Risks of alternate-day prednisone in patients with cystic fibrosis. Pediatrics 1990; 87: 245-246.

27. Konstan MW, Byard PJ, Hoppel CL, Davis PB. Effect of high-dose ibuprofen in patients with cystic fibrosis. $N$ Engl J Med 1995; 332: 848-854.

28. McElvaney NG, Nakamura H, Birrer P, et al. Modulation of airway inflammation in cystic fibrosis. $J$ Clin Invest 1992; 90: 1296-1301.

29. McElvaney NG, Hubbard RC, Birrer P, et al. Aerosol alpha1-antitryspin treatment for cystic fibrosis. Lancet 1991; 337: 392-394.

30. Berger M, Konstan MW, Hilliard J. Aerosolized prolastin ( $\alpha_{1}$-protease inhibitor) in CF. Abstract presented at the 9th Annual North American CF Conference, Dallas, October 1995. 